\title{
Enhanced Human Bone Marrow Mesenchymal Stem Cell Chondrogenic Differentiation in Electrospun Constructs with Carbon Nanomaterials
}

Benjamin Holmes ${ }^{1}$, Xiuqi Fang ${ }^{1}$, Annais Zarate $^{2}$, Michael Keidar ${ }^{1}$ and Lijie Grace Zhang ${ }^{1,3^{*}}$ 


\begin{abstract}
Cartilage as a tissue in the body possesses a low regenerative capacity and is extremely difficult to repair. Today, treatment of cartilage injury, degeneration and defects presents critical clinical challenges, yet none of the currently available cartilage treatments provides a perfect solution. Since natural cartilage extracellular matrix is a nanoscaled structure, the main objective of this study is to design a novel biomimetic nanostructured cartilage construct via electrospinning and carbon nanomaterials for enhancing human bone marrow mesenchymal stem cell chondrogenic differentiation. For this purpose, we synthesized a carbon nanomaterial mixture, using a plasma arc discharge method, consisting of graphene nanoplatelets and single walled carbon nanotubes. This nanomaterial was then incorporated into electrospun polycaprolactone (PCL) microfibrous scaffolds, with and without an additional poly-L-lysine surface coating. Scaffolds were thoroughly characterized for both their biomimetic features and biocompatibility. Our results showed that our scaffolds with carbon nanomaterial have greatly improved mechanical properties and enhanced stem cell adhesion, proliferation and chondrogenic differentiation than PCL controls without carbon nanomaterials, and thus hold promise for improving cartilage formation in future in vivo studies and clinical applications.
\end{abstract}




\section{Introduction}

Hyaline cartilage is an avascular connective tissue, found on the articulate surface of joints. It functions as a shock-absorber, bearing repeated loads throughout a person's lifetime, as well as providing a lubricated surface for smooth joint movement $[1,2]$. Injury to cartilage tissue caused by traumatic injury, disease, or chronic wear is detrimental due to its limited self-healing capacities [2]. The primary cells present in cartilage are chondrocytes, which generate and maintain a nanostructured extracellular matrix (ECM). However, chondrocytes only make up about $2 \%$ of cartilage [3], and tend to stay within the limits of the lacunae [4]. Therefore, following injury, the low cell density of cartilage impedes self-repair. The lack of a vascular network further prevents the infiltration of stem cells from nearby tissues to promote reparative pathways $[1,5]$.

There are many available cartilage treatments such as autografts, allografts, and autologous cell implant [5]. Although promising results have been achieved, they still exhibit many shortcomings. As the most versatile and promising cell source, stem cells have been studied in tissue engineering and regenerative medicine for over a decade and hold great potential in cartilage regeneration [6-9]. However, despite their remarkable potential, one of the major challenges in successfully applying stem cells in functional cartilage tissue regeneration is the difficulty in providing the proper environmental cues to regulate their self-renewal and differentiation [10-16]. Engineering a biomimetic 3D cartilage tissue environment will facilitate deciphering the mechanisms of controlling stem cell behavior and have a profound impact on stem cell based cartilage regeneration [17]. Since human cartilage tissue ECM is a nanocomposite material containing various components like collagen, glycosaminoglycan (GAG) and bioactive factors, etc. [18, 19], nanomaterials with biomimetic features and excellent 
physicochemical properties [20-23] are promising in cartilage regeneration. However, there are only few current studies in the field [24-26].

Thus, this project focused on designing an innovative biomimetic electrospun nanostructured construct via carbon nanomaterials for regulating human bone marrow mesenchymal stem cell (hMSC) growth and chondrogenic differentiation in vitro. The main function of the nano scaffold is to provide a cell-favorable environment which mimics the physical and chemical characteristics of native cartilage ECM and effectively influences hMSC behavior and eventually de novo tissue formation. Electrospinning is a process for creating inherently porous materials composed of micro and/or nano scale polymer fibers. Briefly, a solid polymer is dissolved in an organic solvent to produce a viscous solution which is loaded into a syringe with a blunt point needle or capillary and then mounted in a syringe pump. The expelled mixture is subjected to a high voltage potential over a specific working distance. This causes a redistribution of molecular charge in the polymer chains, drawing a long fiber to a grounded collector plate [27-29]. The solvent evaporates, either due to the voltage applied or natural evaporation in air, and a mesh of solid polymer fibers is created [29-31]. Electrospinning can provide a micro or nanofibrous 3D environment which mimics the arrangement of collagen fibers in deep layers of cartilage, and thus is highly advantageous for cartilage study [32]. A variety of natural and synthetic biocompatible polymers can be electrospun into cartilage scaffolds [32]. Among them, polycaprolactone (PCL) is a synthetic aliphatic polyester which has been FDA approved for biomedical applications, such as sutures and wound dressings, due to its excellent biocompatibility and biodegradability $[33,34]$. In this study, we will use it as a model electrospinning matrix material. Nanofibrous PCL scaffolds have shown the ability to guide hMSC differentiation toward the chondrogenic lineage [33]. Unfortunately, PCL normally lacks 
strong mechanical properties and is hydrophobic, which necessitates modifications to increase initial cell attachment and subsequent proliferation, differentiation and tissue formation. In order to increase cell affinity of PCL scaffolds, we must modify its physicochemical characteristics [35]. Researchers have shown that cationic molecules, such as poly-L-lysine, promote cell adhesion and proliferation by increasing the scaffolds' hydrophilicity [35]. Moreover, the intrinsic mechanical properties of the target tissue, in this case cartilage, cannot be overlooked for mechanical cues are instrumental in guiding cell differentiation [36, 37].

In recent years, carbon nanomaterials such as carbon nanotubes and graphene have attracted increased interests in enhancing mechanical strength of tissue engineered constructs and regulating various cell behaviors [38-41]. For instance, our recent study demonstrated that the inclusion of hydrogen treated multi-walled carbon nanotubes can greatly increase the compressive young's modulus of electrospun polylactic acid scaffolds [25]. In addition, it has been demonstration that magnetically treated single walled carbon nanotubes (SWCNTs) can also improve hMSC adhesion and proliferation on titanium surfaces [40]. Graphene also shows great promise in tissue regeneration applications $[42,43]$. Derived from graphite, it consists of a two-dimensional sheet of carbon atoms arranged in a hexagonal lattice [44, 45]. Sayyar et al. has shown the incorporation of graphene increases both electrical conductivity and mechanical strength of PCL composites [34]. Studies have also shown graphene itself is biocompatible with different cell types and does not adversely affect cell viability nor morphology in vitro and instead stimulates growth; underscoring graphene's amazing potential for tissue formation [38, 39]. Recently, Akhavan et al. demonstrated that graphene nanogrids can serve as a $2 \mathrm{D}$ selective template to significantly improve osteogenic differentiation of human umbilical cord blood mesenchymal stem cells [46]. Given graphene's Young's modulus (1TPa), it is easy to imagine 
how incorporation of this carbon nanomaterial would also reinforce the mechanical strength of an engineered scaffold, further enhancing its biomimetic properties [47].

Hence here we have synthesized a carbon nanomaterial mixture, using a plasma arc discharge method, which consists of graphene nanoplatelets and SWCNTs. We then designed biomimetic electrospun PCL scaffolds which uniquely encompass and utilize these carbon nanomaterials, as well as a poly-L-lysine for improved hMSC function and chondrogenic differentiation in vitro. We expected the integrated carbon nanomaterials and poly-L-lysine mixture would increase the mechanical strength of the scaffolds and promote hMSC function for enhanced cartilage formation.

\section{Experimental}

\subsection{Carbon nanomaterial synthesis and characterization}

The graphene and SWCNTs are synthesized by an arc-discharge method [25, 48, 49]. Arc discharge, which has been widely used for carbon nanotube synthesis, is a cheap, effective and, when properly calibrated, a highly consistent and reproducible method for carbon nanomaterial mass-production. Until very recently, graphene has typically been grown using vapor deposition and catalytic germination. The use of arc-discharge produced graphene can provide a highly cost effective way to produce our novel scaffolds, for much more effective and translatable cartilage defect treatment.

Our arc discharge system consists of a stainless steel cylindrical vacuum chamber (Figure 1) with a total volume of $4500 \mathrm{~cm}^{3}$ (27 cm in length and $14.5 \mathrm{~cm}$ diameter). A cathode and anode was installed along the vertical axis of the chamber. The cathode is a stainless steel rod while the anode is a pure graphite hollow rod which is filled with carbon powder and medal 
catalyst. Carbon powder and the catalyst powder of nickel and yttrium were mixed and filled into the anode rod with a total molar ratio of 56:4.2:1. Initially the chamber was pumped to the pressure of about $10^{-1}$ torr, then high purity helium was introduced and the pressure was kept at around 500 Torr with an Omega CN-8502 controller. Experiments were conducted with a constant power supply and a fixed arc current of about 75A. In regard to the graphene synthesis, a discharge enhancing/separating magnet unit (DESMU) was added into this chamber, so that both SWCNTs and graphene were produced simultaneously. Once synthesized, the graphene and nanotubes were collected and analyzed via scanning electron microscopy (SEM) and Raman spectroscopy. For all of the following studies, we used a mixture of graphene and SWCNTs ( 60 $\%$ nanotubes, $30 \%$ graphene and $10 \%$ amorphous carbon), which will be referred to here as carbon nanomaterials.
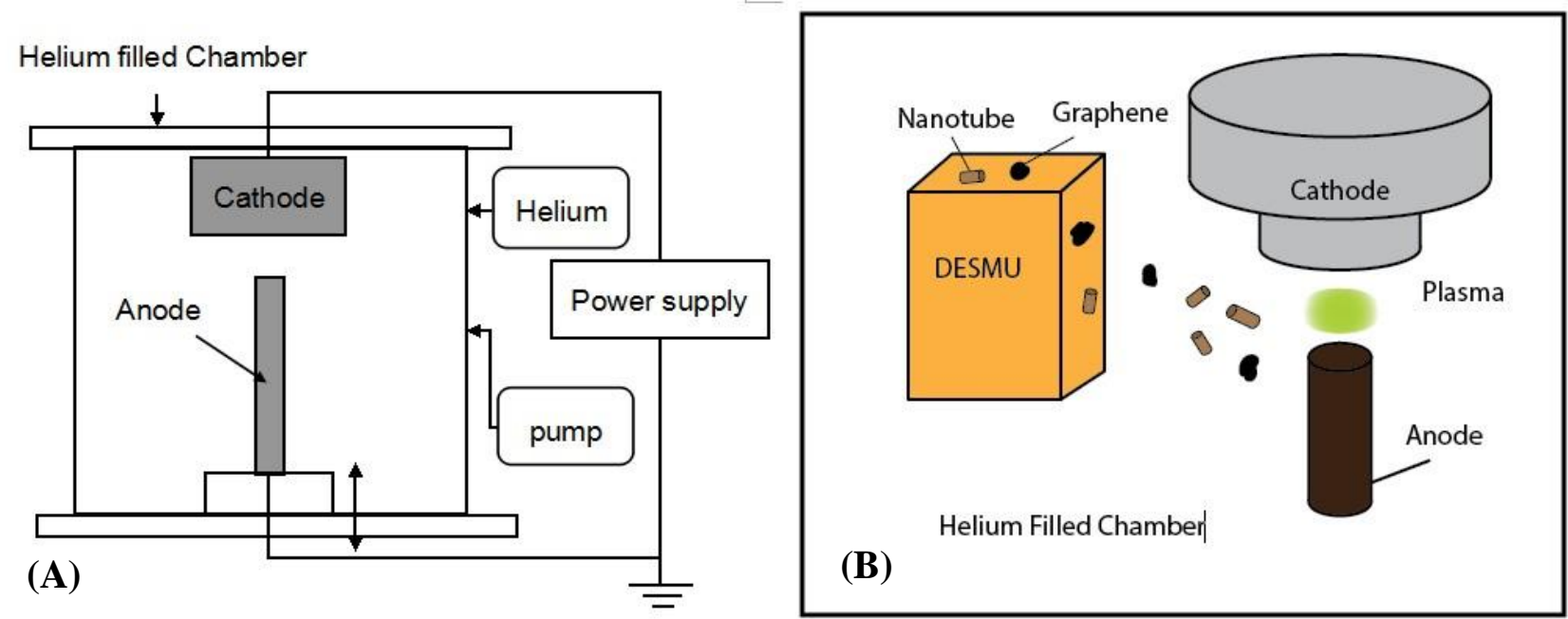

Figure 1. Schematic diagrams of (A) the vacuum chamber in all experimental setup; and (B) the detailed carbon nanomaterial synthesis. This setup can be also used to generate pure SWCNTs, or our nanotubegraphene nanoplatelet mixture.

\subsection{Electrospinning PCL microfibrous scaffolds with carbon nanomaterials}


Figure 2 shows the overview of the following experimental design. A classical electrospinning set-up was employed to create all scaffolds in which a blunt tip $5 \mathrm{~mL}$ needle was connected to both a syringe pump and a voltage source; the fibers were collected on a conductive aluminum plate. The working distance and flow rate were kept constant at $13.5 \mathrm{~cm}$ and $0.5 \mathrm{~mL} /$ hour, respectively. The voltage ranged from $6-8 \mathrm{kV}$. The polymer PCL (molecular weight around 80k), was the matrix component of all experimental groups. For the control, $0.6 \mathrm{~g}$ PCL was dissolved in $5 \mathrm{~mL}$ chloroform after 45 minutes of sonication and then electropsun. $0.5 \%$ graphene/nanotube embedded PCL scaffolds were fabricated by sonicating $0.25 \mathrm{mg}$ graphene/nanotube in $5 \mathrm{~mL}$ chloroform for 10 minutes prior to adding PCL to produce a homogenous mixture. $1.0 \%$ graphene/nanotube was made in a similar fashion using $0.5 \mathrm{mg}$ graphene. To apply the poly-L-lysine coating, $1 \mathrm{~mL}$ of poly-L-lysine and $0.75 \mathrm{mg}$ graphene/nanotube were sonicated for 1 hour and excess poly-L-lysine was allowed to evaporate

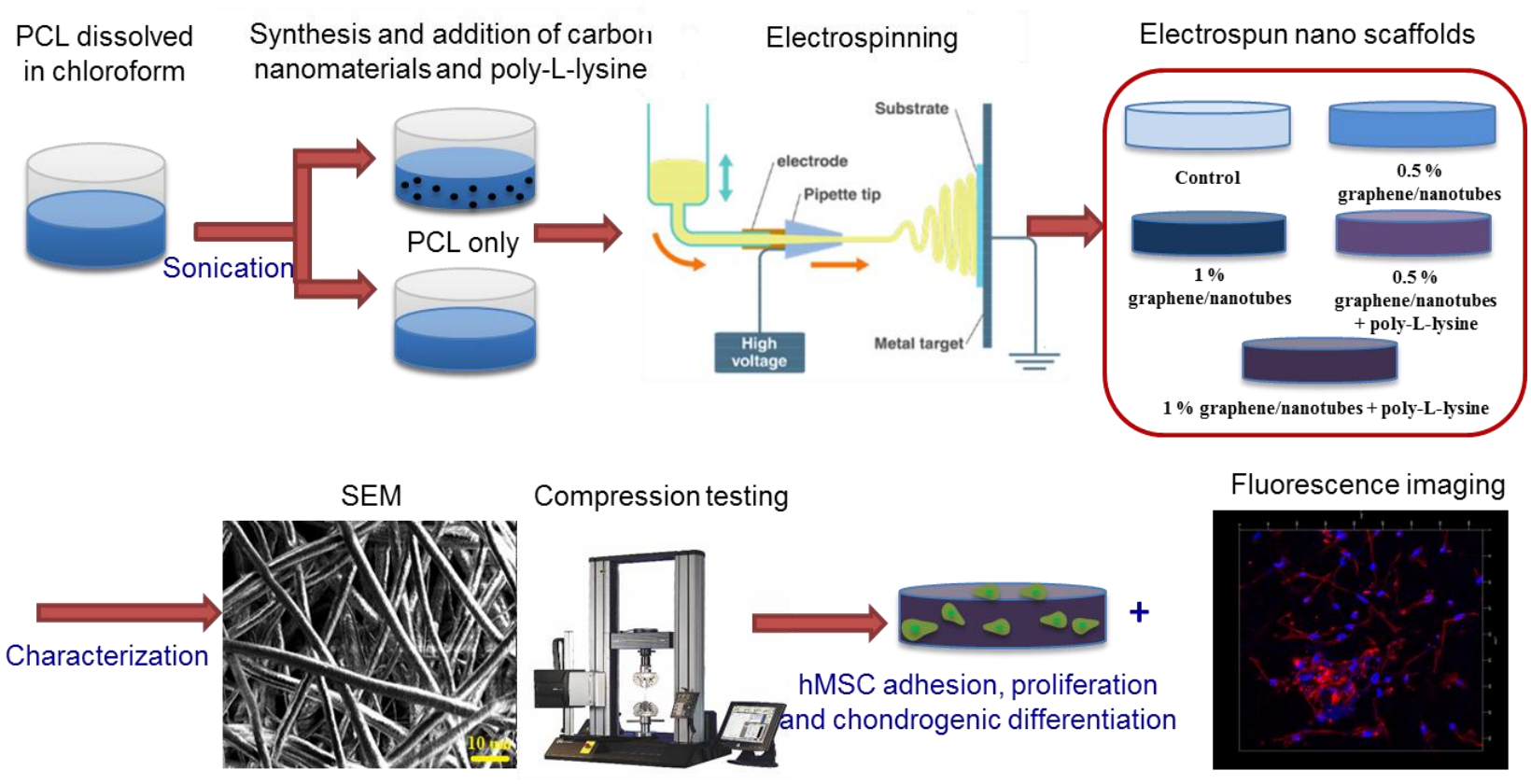

Figure 2. Schematic diagram of the overall experimental design. 
for 48 hours. Subsequently, $0.5 \%$ and $1.0 \%$ poly-L-lysine coated graphene/nanotube was then incorporated into PCL scaffolds as described above. $5 \mathrm{~mm}$ biopsy punches were used to cut samples for the following characterization and cell studies.

\subsection{Scaffold characterization}

Electrospun scaffolds were imaged via SEM to assess fiber morphology and size. All samples were sputter coated with gold for 8 seconds (sputter set point 40 mTorr vacuum pressure) and visualized with a Zeiss SigmaVP SEM. Compressive mechanical testing was conducted on a table-top uniaxial mechanical tester. The tester consisted of a $30 \mathrm{~cm}$ tall screw driven piston operated by a hand crank. The average strain rate was $0.07 \mathrm{~cm} / \mathrm{min}$, which is intended to simulate a static loading scenario. Three samples $(5 \mathrm{~mm}$ in diameter and $1.5 \mathrm{~mm}$ in height) from each group were tested. Displacement and force data were used to calculate the Young's modulus.

Specific protein (i.e., fibronectin) absorption on the scaffolds was investigated using a well-established enzyme-linked immunosorbent assay (ELISA) to elucidate the possible underlying mechanism of hMSC responses in different scaffolds [50]. Briefly, $5 \mathrm{~mm}$ diameter samples were taken and affixed to the bottom of 48 well plate wells, washed once with PBS and then incubated for four hours in $500 \mu \mathrm{l}$ of $25 \mu \mathrm{g} / \mathrm{ml}$ fibronectin solution. After PBS rinsing, nonspecific fibronectin adsorption on the scaffolds was blocked by soaking in $2 \%$ bovine serum albumin (BSA) for $1 \mathrm{~h}$. Fibronectin was then bound to a primary rabbit anti-bovine fibronectin antibody for $1 \mathrm{~h}$. The samples were further incubated with a secondary goat anti-rabbit antibody conjugated with horseradish peroxidase for $1 \mathrm{~h}$. After washing with $0.05 \%$ Tween 20, the amount of fibronectin absorption on our electrospun scaffolds was measured with an ABTS 
substrate kit. The secondary antibody binding was detected using a microplate spectrophotometer at an absorbance wavelength of $405 \mathrm{~nm}$.

\section{4 hMSC cell studies in vitro}

\subsection{1 hMSC culture}

hMSCs obtained from the Texas A\&M Health Science Center, Institute for Regenerative Medicine were used to evaluate cell adhesion, proliferation, and chondrogenic differentiation in the our novel electrospun nano scaffolds. hMSCs with passage \# 3 were cultured in complete media encompassing alpha minimum essential medium, $16 \%$ fetal bovine serum, $1 \%$ Lglutamine, $1 \%$ penicillin/ streptomycin and incubated under standard cell culture conditions $\left(37^{\circ} \mathrm{C}\right.$, a humidified, $5 \% \quad \mathrm{CO} 2 / 95 \%$ air environment). For chondrogenesis, $100 \mathrm{nM}$ dexamethasone, $40 \mu \mathrm{g} / \mathrm{mL}$ proline, $100 \mu \mathrm{g} / \mathrm{mL}$ sodium pyruvate, $50 \mathrm{mg} / \mathrm{mL}$ L-ascorbic acid 2phosphate and $1 \%$ ITS+ were added to the above complete media. Media was replaced every other day. Prior to cell seeding, all scaffolds were sterilized under UV light for 15 minutes on both sides.

\subsection{2 hMSC adhesion and proliferation studies}

To gauge the efficacy of the scaffolds to promote cell attachment, cells were seeded at a density of 10,000 cells per scaffold in a 48 well plate, on circular samples with $5 \mathrm{~mm}$ in diameter and $1.5 \mathrm{~mm}$ in height. After a four hour culture, trypsin-EDTA was added to each sample to lift hMSCs and neutralized with complete media. $100 \mu \mathrm{L}$ of cell solution was transferred to a 96 well plate and $40 \mu \mathrm{L}$ of Promega MTS assay dye (a CellTiter 96® AQueous Non-Radioactive Cell Proliferation Assay) was added. The plate was incubated at $37^{\circ} \mathrm{C}$ for an additional hour and absorbance was read at $490 \mathrm{~nm}$ using a Thermo Scientific Multiskan GO spectrophotometer. 
For cell proliferation study, all samples were seeded at a density of 10,000 cells/ scaffold and incubated for 1, 3 and 5 days. At each time point, scaffolds were trypsinized and incubated prior to neutralization with complete media. The cell proliferation on each scaffold was quantified by Promega MTS assay and read at $490 \mathrm{~nm}$ wavelength. In addition, in order to image hMSC spreading and distribution morphologies, hMSCs were fixed using $10 \%$ formaldehyde and $0.1 \%$ Triton X-100 for 15 min. The nuclei of hMSCs were stained with DAPI and F-actin filaments and the cytoskeleton were stained with Texas Red-phallodin. Cell morphologies were evaluated by imaging the stained and fixed samples under a Zeiss 710 confocal microscope. All images were taken as multi-focal Z-stacks and then then linear unmixed, post-processed and collated using the ZEN software package.

\subsubsection{Two week hMSC chondrogenic differentiation study}

All scaffolds for differentiation study were seeded at a density of 50,000 cells / scaffold. Samples incubated in chondrogenic media were collected after 1 and 2 weeks to evaluate hMSC chondrogenesis. Media was removed from the samples and rinsed with PBS, frozen at $-80{ }^{\circ} \mathrm{C}$ for 4 hours, and lyophilized for 24 hours. $500 \mu 1$ of Papain digestion was then added to each sample and heated at $60^{\circ} \mathrm{C}$ for 24 hours.

The most important chondrogenic marker--GAG content was quantified using a Blyscan $^{\mathrm{TM}}$ GAG assay kit. Specifically, $100 \mu \mathrm{L}$ of sample diluent were added to $1.5 \mathrm{~mL}$ centrifuge tubes. $500 \mu \mathrm{L}$ of Blyscan dye reagent was added to each tube and placed on a shaker for 30 minutes. All samples were centrifuged at 10,000 RPM for 20 minutes to get GAG-dye complex pellet. The tubes were drained and $600 \mu \mathrm{L}$ of dissociation reagent was added. The tubes were again centrifuged at 10,000 RPM for 5 minutes. $200 \mu \mathrm{L}$ of the solution was transferred to well on a 96 well plate and absorbance read at $656 \mathrm{~nm}$. 
Type II collagen synthesis was characterized by a collagen type II ELISA assay according to the manufacturer's instructions. First, $40 \mu \mathrm{L}$ of sample diluent was added to each well in the collagen coated 96 well plate. $10 \mu \mathrm{L}$ of digested sample solution was then added and the well plate was placed on a shaker for 2 minutes before incubating for 30 minutes at $37{ }^{\circ} \mathrm{C}$. The samples were rinsed four consecutive times with PBS, $50 \mu \mathrm{L}$ of horse radish peroxidaselabeled collagen II antibody was added, and incubated for 30 minutes. After washing, $50 \mu \mathrm{L}$ of both chromogen A and B were added and incubated for 30 minutes, in succession, with another PBS wash in-between. The reaction was stopped by the addition of $50 \mu \mathrm{L}$ acidic stop solution and absorbance was read at $450 \mathrm{~nm}$ using a photometric plate reader.

\subsection{Statistical analysis}

All quantitative cellular experiments were run in triplicate and repeated three times for each substrate. Data were expressed as mean \pm standard error of the mean and analyzed with a Tukey's post-hoc test to determine differences amongst the groups. Statistical significance was considered at $\mathrm{p}<0.05$.

\section{Results and discussion}

\subsection{Development of novel electrospun nano scaffold with carbon nanomaterials}

\subsubsection{Graphene and SWCNT based carbon nanomaterial}

SWCNTs were collected around the cathode and the chamber wall while graphene nanoplatelets were collected from the side and top surface of the DESMU. Figure 3 shows the representative SEM images (Figures 3A-D) and Raman spectra (Figures 3E-F) of SWCNTs and graphene samples produced by the plasma arc discharge method. Figure 3A shows the densely packed SWCNTs and Figure 3B shows the isolated graphene nanoplatelets. Figures 3C-D 
shows SEM images of the carbon nanomaterial composed of both of SWCNTs and graphene, as it appears when taken out of the arc discharge chamber and is newly synthesized.
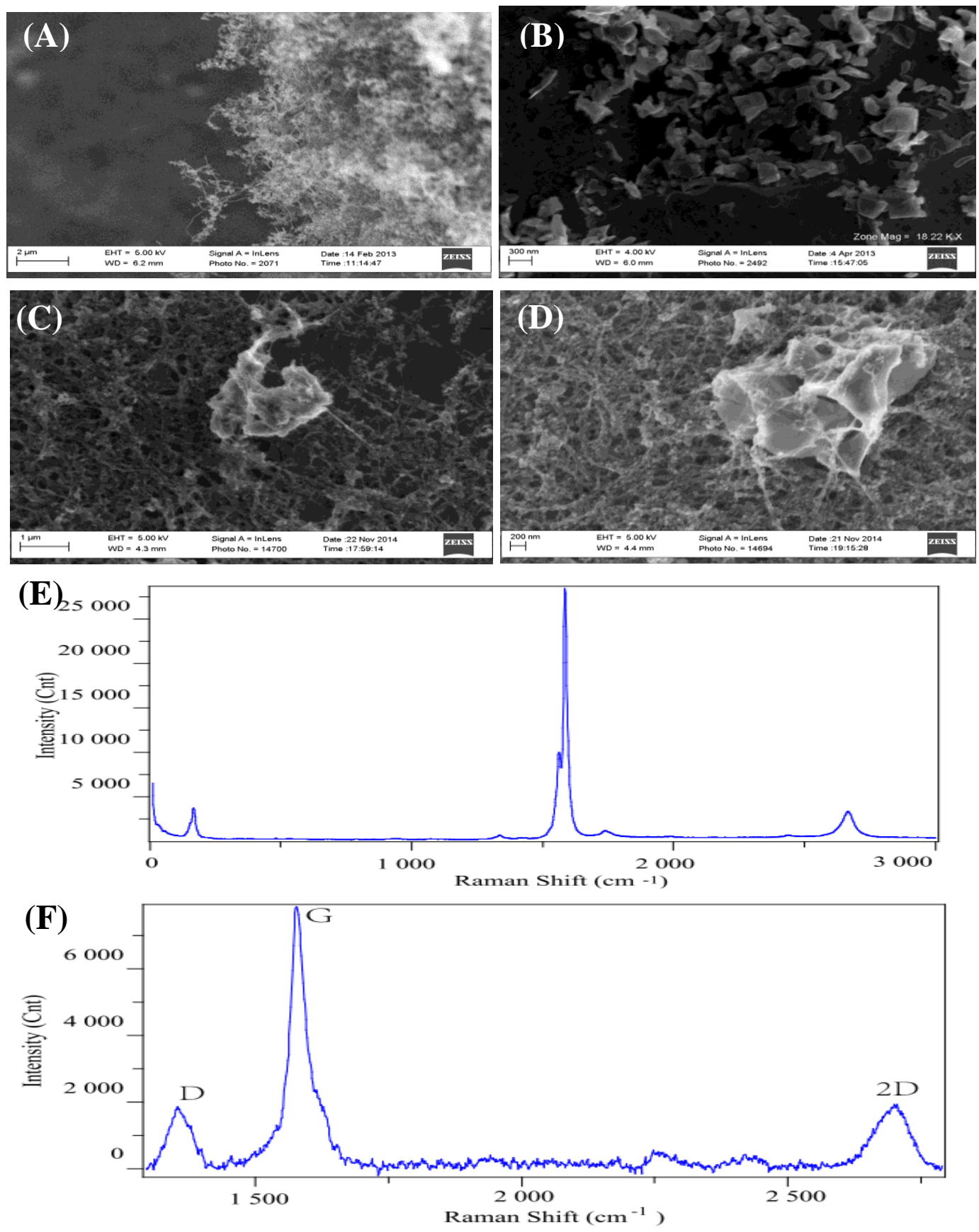

Figure 3. SEM images of (A) SWCNTs; (B) graphene nanoplatelets; and (C-D) the SWCNTs and graphene composite. Raman spectrum of (E) SWCNTs and (F) graphene nanoplatelets. 
Raman spectroscopy is an important tool to characterize SWCNT and graphene. The Radial breathing mode (RBM) between 120 and $350 \mathrm{~cm}^{-1}$ was used to measure the diameter of nanotube by the coherent vibration frequency $\left(\omega_{\mathrm{RBM}}\right)$ of the carbon atoms in the radial direction. The SWCNT diameter can be calculated by solving the following equation: $\omega_{\mathrm{RBM}}=\mathrm{A} / \mathrm{d}_{\mathrm{t}}+\mathrm{B}$; Where $\mathrm{A}=234 \mathrm{~cm}^{-1}$ and $\mathrm{B}=10 \mathrm{~cm}^{-1}$. For this typical SWCNT, the major RBM peaks is showed in the Raman spectrum which is $162.7 \mathrm{~cm}^{-1}$, so the average diameter of the nanotube can be estimated as $1.53 \mathrm{~nm}$.

Two typical peaks in the Raman spectrum are used to identify graphene nanoplatelets: $G$ peak $\left(\sim 1580 \mathrm{~cm}^{-1}\right)$ and 2D peak $\left(\sim 2690 \mathrm{~cm}^{-1}\right)$. 2D peak is a second-order overtone of D peak $\left(\sim 1350 \mathrm{~cm}^{-1}\right)$ which place an important role in characterization of graphene. Both $\mathrm{D}$ and 2D peak positions depend on the laser excitation energy. In this experiment, the position cited was from a $532 \mathrm{~mm}$ excitation laser.

\subsubsection{Electrospun fibrous scaffold characterization}

Figure 4 shows the SEM images of all electrospun fibrous scaffolds. It can be seen that all scaffolds (control and carbon nanomaterials incorporating scaffolds) exhibited micron fibers in randomly oriented distributions. The goal of carbon nanomaterial and poly-L-lysine addition to a PCL is to achieve fibers with improved mechanical characteristics, nano surface topography and cell-favorable surface chemistry, while maintaining the size and scale of the electrospun fibers. The SEM images show that the incorporation of graphene/nanotube as well as poly-Llysine into electrospun scaffolds (Figures 4B-4E) can contribute to a more homogenous distribution of fiber dimensions and improved morphology when compared to the electrospun pure PCL scaffold (Figure 4A). Specifically, electrospun PCL control scaffolds (Figure 4A) have a wide range of fiber diameters. With the addition of graphene/nanotube, there is less 
presence of very fine fibers (under $1 \mu \mathrm{m}$ ), but generally observed fibers have a more uniform distribution of diameters.
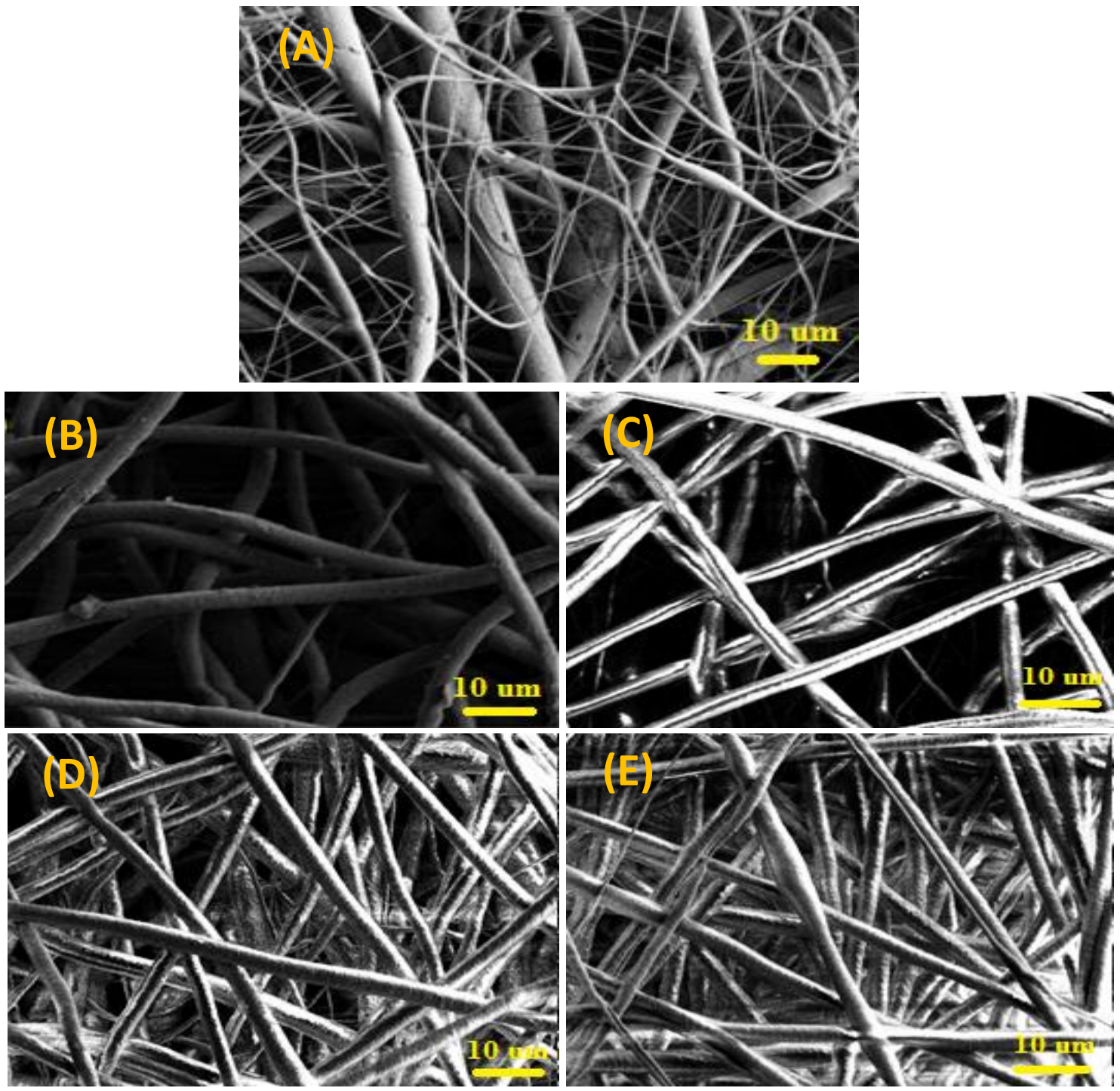

Figure 4. SEM images of electrospun microfibrous scaffolds with different nanomaterial composition: (A) pure PCL control, (B) $0.5 \%$ graphene/nanotube, (C) $1.0 \%$ graphene/nanotube, (D) $0.5 \%$ and (E) $1.0 \%$ poly-L-lysine coated graphene/nanotube scaffolds. 
Compressive mechanical testing was conducted on control PCL scaffolds, and scaffolds containing $0.5 \%$ and $1.0 \%$ carbon nanomaterial. The compressive young's modulus (Figure 5) clearly shows that graphene/nanotube even in a low concentration can improve the PCL scaffold mechanical properties. In addition, as the amount of carbon nanomaterial in the polymer was increased, the young's modulus of the scaffolds also increased. Coupled with our SEM images, this demonstrates our ability to include nano constituents in an electrospun polymer to improve mechanical properties and microfibrous morphology. This also shows the effectiveness of our arc discharge synthesized graphene nanoplatelets and SWCNTs as nanoconstituents to improve mechanical performance of electrospun scaffolds.

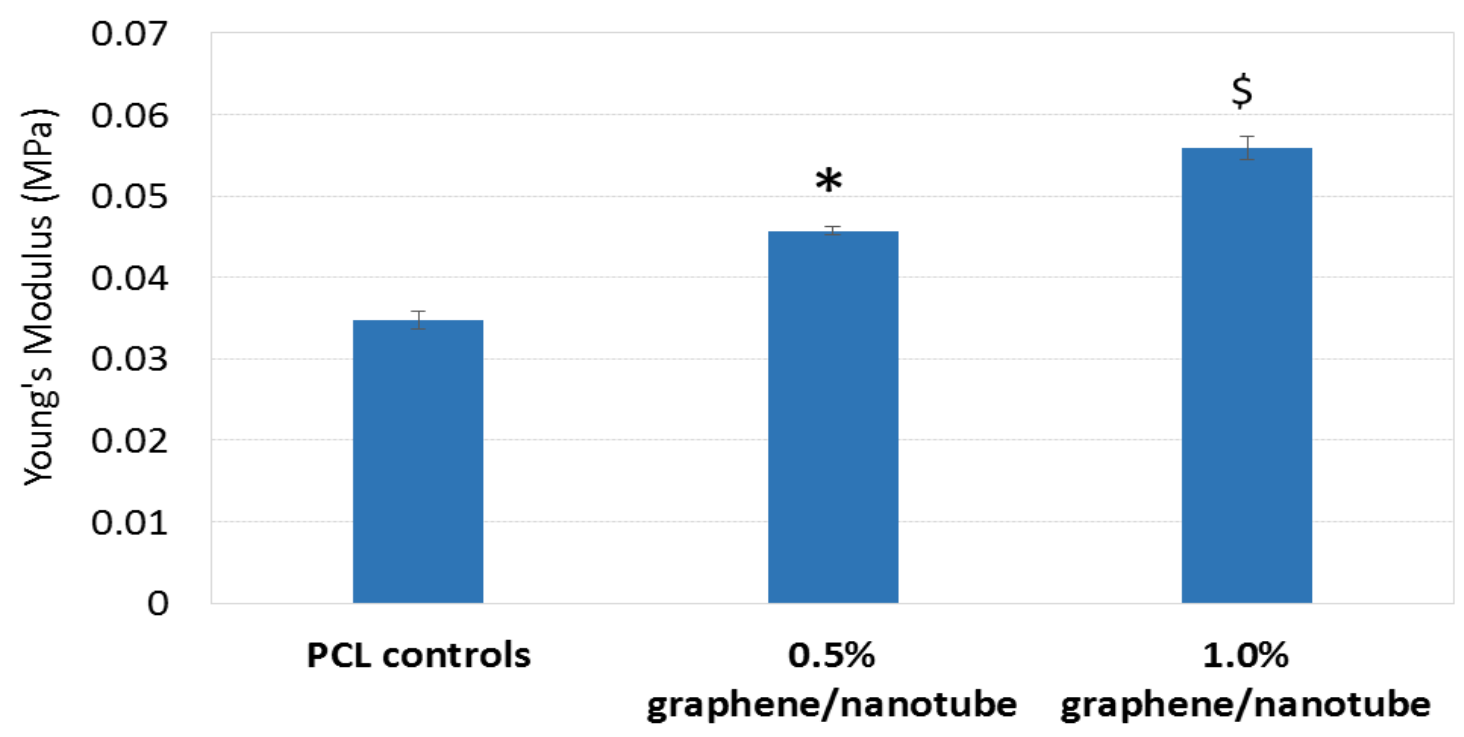

Figure 5. Young's modulus for control, $0.5 \%$ and $1.0 \%$ graphene/nanotube scaffolds. Data are standard error of the mean, $n=3 ; \$ p<0.05$ when compared to all other scaffolds and $* \mathrm{p}<0.05$ when compared to controls.

In order to further understand specific protein absorption on these nanostructured scaffolds, we performed fibronectin ELISA measurements. Our result (Figure 6) showed significantly greater amounts of fibronectin absorptions in $1.0 \%$ graphene/nanotube, $0.5 \%$ and 
$1.0 \%$ poly-L-lysine coated graphene/nanotube scaffolds. In addition, scaffolds with $0.5 \%$ graphene/nanotube with no poly-L-lysine coating did not improve fibronectin adsorption. Protein adsorption can be influenced by many factors including scaffold surface chemistry, charge, wettability, roughness, fiber morphology, etc. Based on our results, $1 \%$ graphene/nanotube or poly lysine coating may provide a more advantageous surface for specific protein adsorption activity when compared to lower concentration scaffolds. Moreover, previous studies have demonstrated that the initial specific protein adsorption (such as fibronectin and vitronectin) can be related to cell functions on a material's surface [51-54]. In the present work, greater fibronectin adsorptions were observed on our nano scaffolds, which is an indicator of both the biomimetic enhancement potential of poly-L-lysine coated nanomaterial, and agrees with our initial hMSC attachment results discussed in the next section.

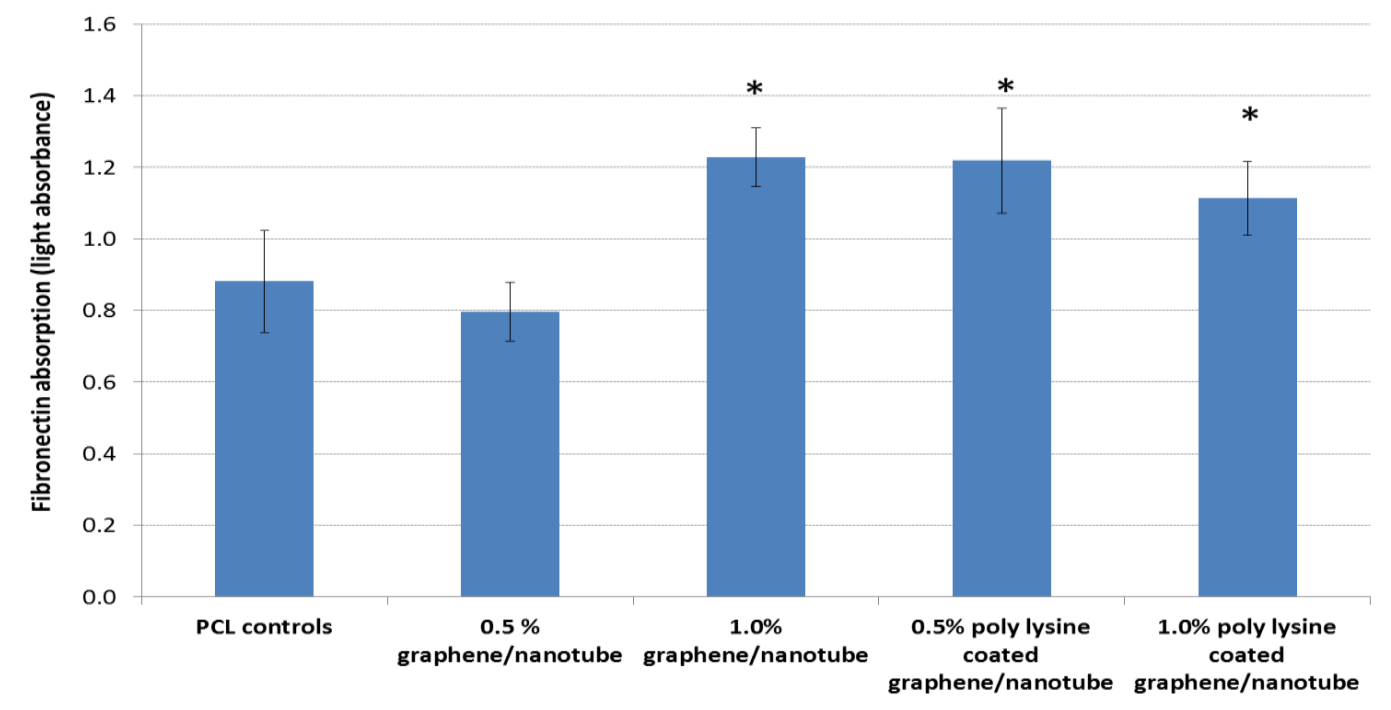

Figure 6. Fibronectin absorption of carbon nanomaterial embedded scaffolds. The greatest absorption was displayed on the $1.0 \%$ and both poly-L-Lysine coated carbon nanomaterial scaffolds. Data are mean \pm standard error of the mean; $n=5 ;{ }^{*}<0.05$ when compared to $0.5 \%$ graphene/nanotube scaffold.

\subsection{Enhanced hMSC functions on electrospun nano scaffold with carbon nanomaterials}




\subsection{1 hMSC adhesion and proliferation}

Figure 7 shows data for 4 hour hMSC adhesion on control and carbon nanomaterial PCL scaffolds. $1.0 \%$ Poly-L-lysine coated graphene/nanotube scaffold had the greatest hMSC adhesion. It has been shown that MSCs prefer to adhere, initially, to stiffer substrates $[36,55]$. The $1.0 \%$ poly-L-lysine coated graphene/nanotube scaffolds provide both a stiffer substrate and a positively charged surface (originated from poly-L-lysine), which can contribute to a more cell adhesive surface for MSC adhesion than other fabricated scaffolds.

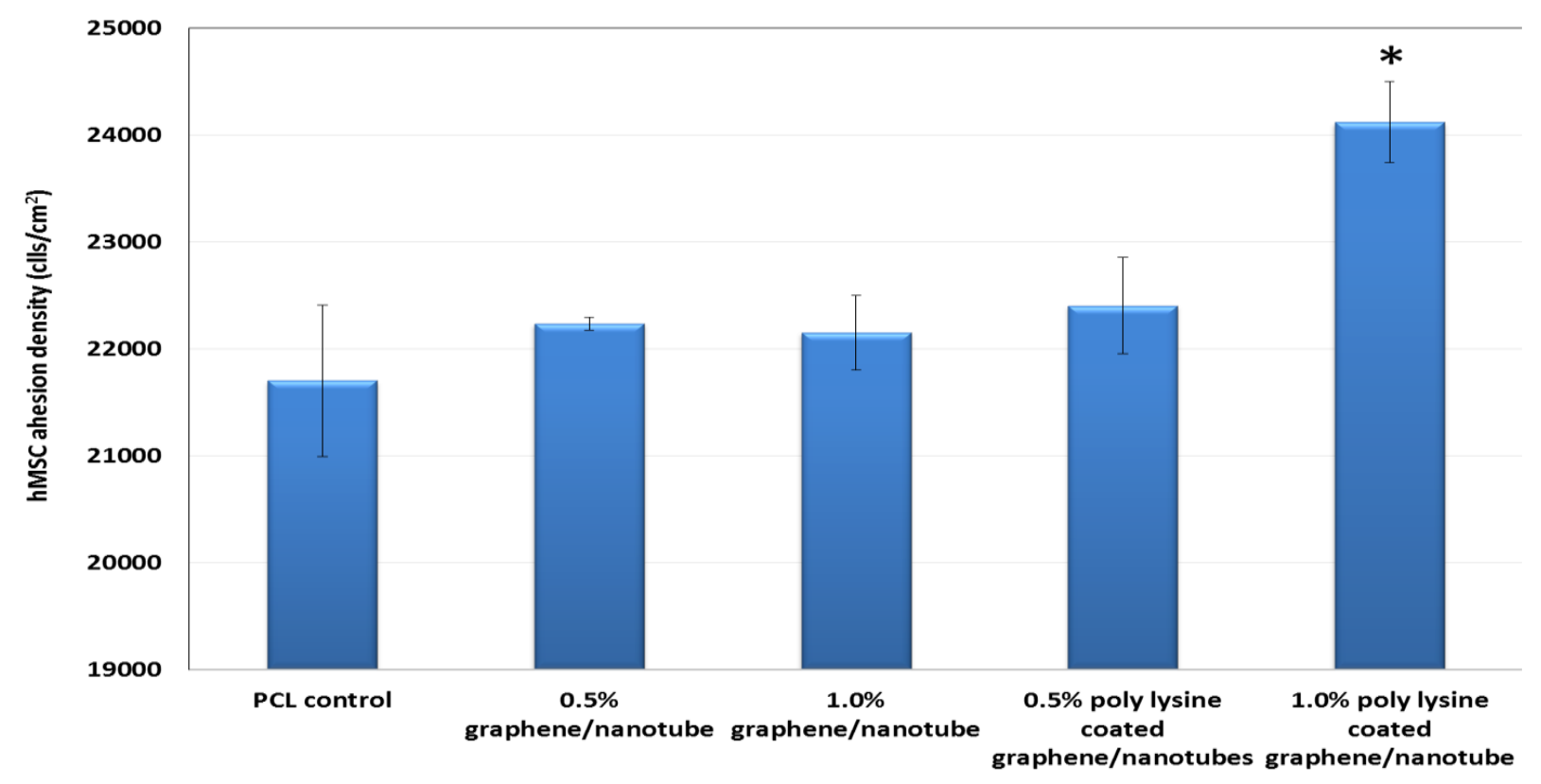

Figure 7. Poly-L-lysine coated graphene/nanotube PCL scaffolds exhibited the greatest hMSC adhesion. Data are mean \pm standard error of the mean; $\mathrm{N}=3,{ }^{*} \mathrm{p}<0.07$ compared to all other scaffolds.

Figure 8 shows enhanced hMSC proliferation on scaffolds with carbon nanomaterials and poly-L-Lysine. The greatest hMSC proliferation after 5 days was observed on the $1.0 \%$ polyL-lysine coated graphene/nanotube scaffolds. hMSC also grew well on the $0.5 \%$ graphene/nanotube scaffolds and the poly-L-lysine graphene/nanotube scaffolds during 5 days of culture. Current results suggest that both the graphene/nanotube composite and poly-L-lysine can 
contribute to improving hMSC proliferation. In addition, hMSC growth on $1.0 \%$ graphene/nanotube scaffold without poly-L-lysine was similar to PCL control with no cell density increase after 5 days. This may also suggest that poly-L-lysine plays a more critical role in regulating hMSC growth via enhancing the electrostatic interaction between the negativelycharged cell membrane and the scaffolds' surface in our study, when compared to hydrophobic graphene/nanotube contribution.

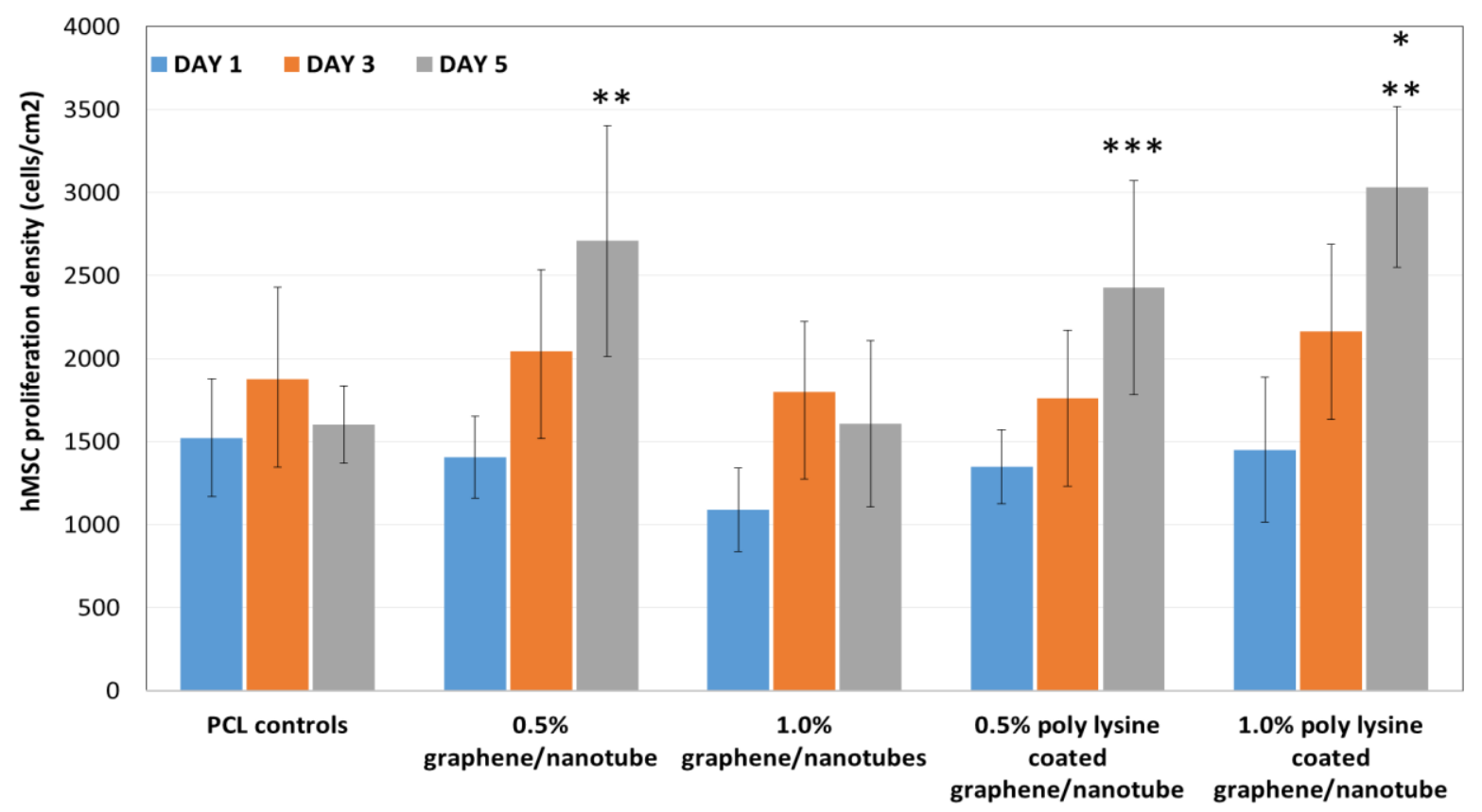

Figure 8. Enhanced hMSC proliferation on various nano scaffolds after 5 days. Data are mean \pm standard error of the mean, $\mathrm{N}=3,{ }^{*} \mathrm{p}<0.05$ when compared to controls and $1.0 \%$ graphene/nanotube embedded PCL scaffolds; **p<0.05 when compared to the respective scaffolds at day 1; and $* * * \mathrm{p}<0.05$ when compared to $1.0 \%$ graphene/nanotube embedded PCL scaffolds.

Figure 9 illustrates confocal microscopy images of hMSC growth and spreading morphologies on all scaffolds after 3 and 5 days of culture. Greatly improved cell density, long filopodia and interconnected cytoskeletal network can be seen on scaffolds with poly-L-lysine coated graphene/nanotube after 5 days. Pure PCL control scaffolds have lower cell growth 
density even after 5 days. Overall, we may postulate that this is due to the improved surface properties and mechanical properties of our composite scaffolds after incorporating graphene/nanotube and a poly-L-lysine coating.

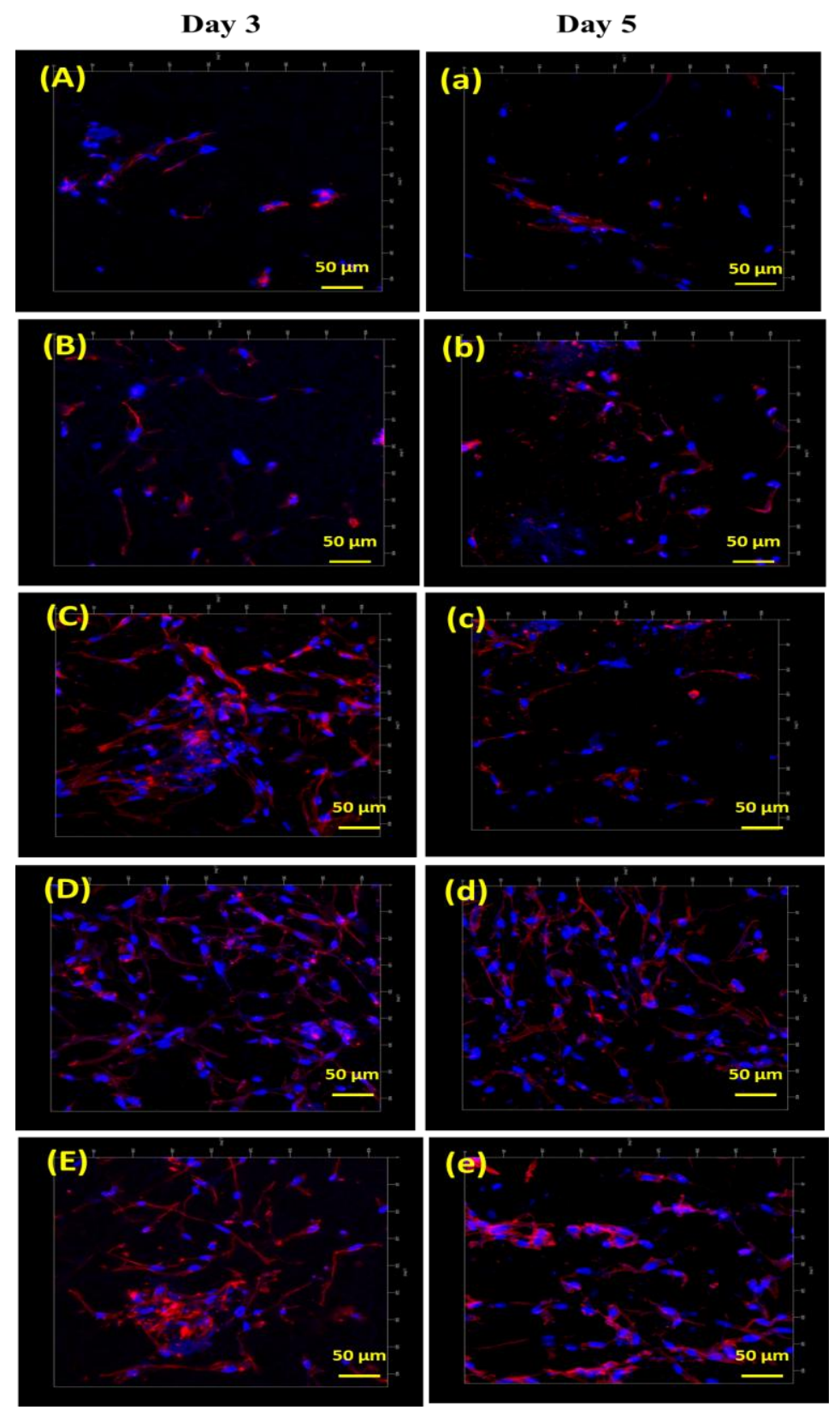

Figure 9. Enhanced hMSC proliferation and spreading morphology on various nano scaffolds after 3 and 5 days. (A-a) control pure PCL scaffold, (B-b) $0.5 \%$ graphene/nanotube scaffold, (C-c) $1 \%$ graphene/nanotube scaffold, (D-d) $0.5 \%$ poly-L-lysine coated graphene/nanotube scaffold, and (E-e) $1.0 \%$ poly-L-lysine coated graphene/nanotube scaffold. 
Cellular adhesion and proliferation studies demonstrated the excellent hMSC cytocompatibility of the designed electrospun microfibrous scaffolds with graphene/nanotube and poly-L-lysine. In the human body, stem cells are very sensitive to even minute physical and chemical changes in their surrounding environment. In our study, both graphene, SWCNTs and poly-L-lysine have been used to modify the physical and chemical properties of our electrospun scaffolds. Specifically, poly-L-lysine has been long-established as a beneficial chemical compound for promoting cellular growth, and recently has been used in regenerative studies [56]. It has been used to modify the surface chemistry of carbon nanotubes to improve their biocompatibility [25]. Here we employed poly-L-lysine to enhance the cytocompatibility and cell adhesive properties of the SWCNTs and graphene nanoplatelets. Besides the favorable poly-Llysine effects on improving hMSC growth discussed above, mechanical properties of biomaterial scaffolds also play a critical role in stem cell development $[57,58]$. Stem cells often are directed by both the mechanical stress and strain interactions of adhesion proteins, signaling nodes and spatial changes in varying mechanical properties to direct cell migration, growth and different differential lineages. It is important to design a scaffold which mimics the mechanical characteristics of any tissue, but for cartilage and other skeletal tissues this becomes essential. Not only do the mechanical properties of the microenvironment influence cell growth but the fashion in which stress and force propagate through the matrix (e.g. when a joint is put under normal load from walking) has profound effects on cell behavior. A prime example of this in the clinic is bone marrow edema, where unnatural concentrations of stress on a person's bones cause cells (including hMSCs) to migrate away from the site of concentrated force, causing weakness and eventually erosion $[59,60])$. Alternatively, appropriate mechanical force can provide a strong environment for advantageous hMSC behavior and desirable differentiation. Thus, the 
improved mechanical strength of our scaffolds with graphene/nanotube may also contribute to the improved hMSC behaviors.

\subsubsection{Enhanced hMSC chondrogenic differentiation on the nanocomposite scaffolds}

2 week chondrogenic differentiation of hMSCs was evaluated on the electrospun nano scaffolds in vitro. GAG and collagen type II are two of the major components of cartilage ECM [61-63], and thus were chosen as important indicators of hMSC chondrogenesis. Figure 10 shows that all of the scaffolds with carbon nanomaterials greatly enhanced GAG synthesis at week 2 when compared to controls. At week 1, the $0.5 \%$ graphene/nanotube scaffolds showed higher GAG deposition than controls. In addition, Figure 11 showed the collagen type II synthesis of hMSCs on our nano scaffolds after 2 week of culture. Both of $0.5 \%$ and $1.0 \%$ poly-

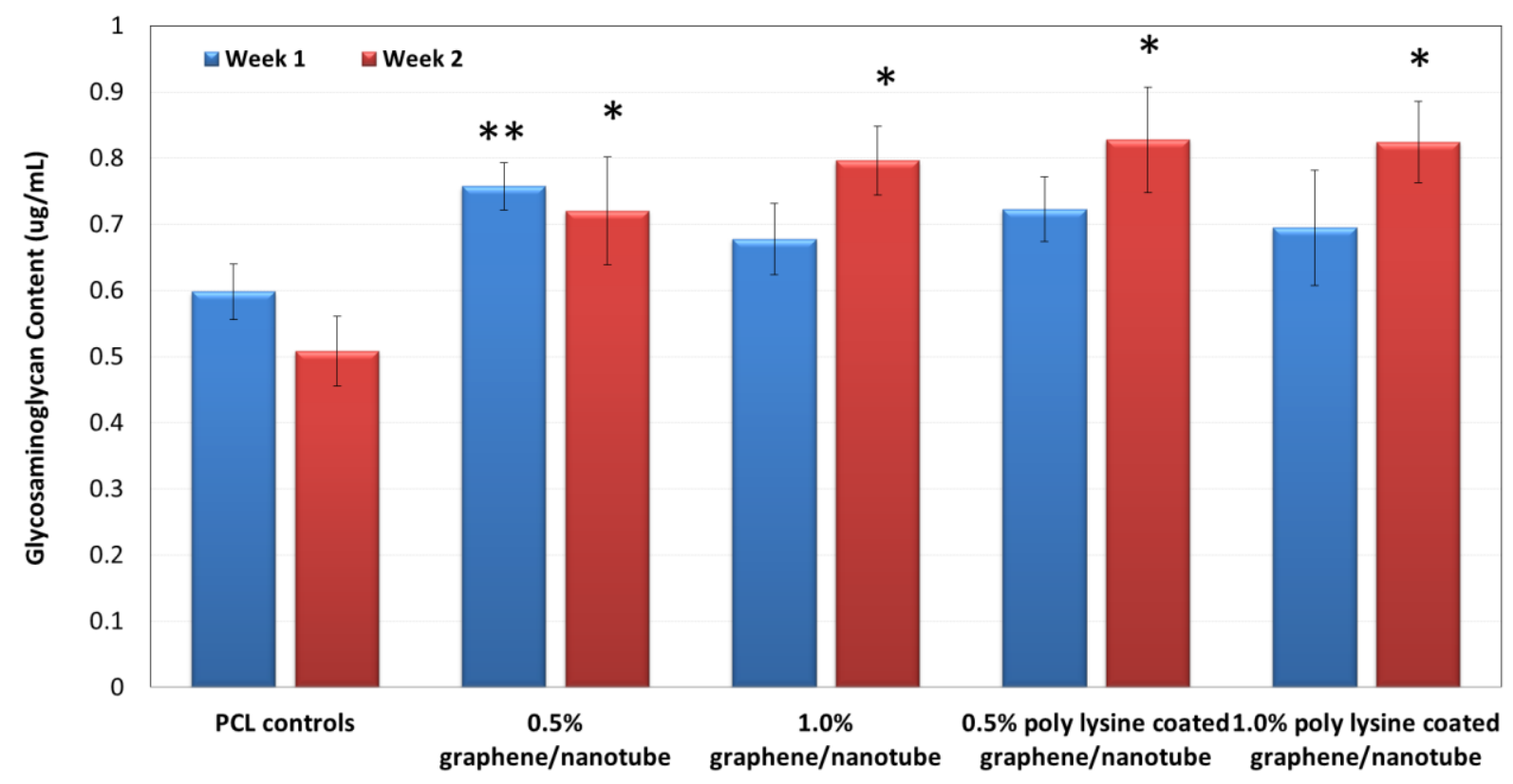

Figure 10. Greatly enhanced GAG synthesis on electrospun nano scaffolds after 2 weeks when compared to PCL controls. Data are mean \pm standard error of the mean, $\mathrm{N}=3$, $* \mathrm{p}<0.05$ when compared to controls after week $2, * * \mathrm{p}<0.01$ when compared to controls after week 1. 
L-lysine coated graphene/nanotube scaffolds generated more collagen type II deposition than controls at the earlier time point. At 2 weeks, the $0.5 \%$ and $1.0 \%$ graphene/nanotube scaffolds induced more collagen type II deposition than controls. The collagen type II content on $1.0 \%$ poly-L-lysine coated graphene/nanotube didn't improve after week 2.

As we know, cartilage is a dense network of proteins and extracellular components with a low density of disperse primary cells (chondrocytes) [5]. GAG, which makes up an important part of the ECM, caries and contributes a high negative charge to the environment. The presence of positively charged poly-L-lysine coated graphene and nanotubes, which can play a very important role in improving cell adhesion, proliferation and GAG productions due to electrostatic interactions with the cell membrane and with negatively charged GAG [64]. It may

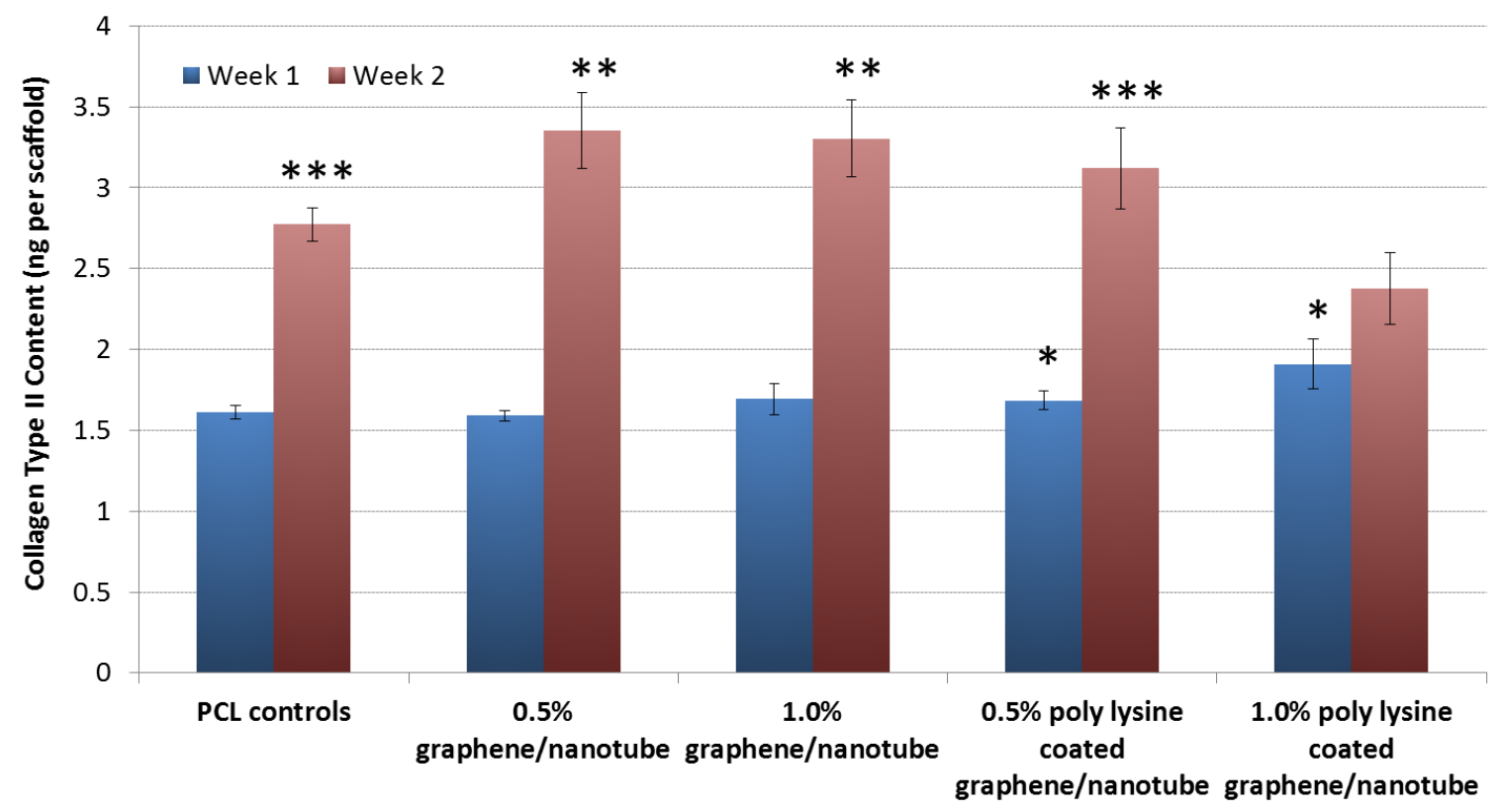

Figure 11. Improved collagen type II synthesis on PCL scaffolds containing carbon nanomaterials. Data are mean \pm standard error of the mean, $\mathrm{N}=3 ; * \mathrm{p}<0.05$ when compared to controls at week 1 ; $* * \mathrm{p}<0.05$ when compared to controls and $1.0 \%$ poly-L-lysine coated graphene/nanotube scaffolds at week $2 ; * * * \mathrm{p}<0.05$ when compared to $1.0 \%$ poly-L-lysine coated graphene/nanotube scaffolds at week 2. 
play a less role in improving collagen synthesis after 2 weeks.

One novelty in our design lies in the use of arc discharge synthesized graphene and SWCNTs as strengthening nano agents in a microfibrous matrix. Currently graphene synthesis is costly and slow, relying on chemical deposition and germination processes to produce highly ordered graphene in any useful quantity. Therefore, the use of an inexpensive, high yield method to produce useful graphene could pave the way towards successfully marketable and clinically applicable / viable regenerative implants. Also, arc discharge, once refined, could provide a way to easily custom tailor the properties of graphene for specific tissue engineering and medical applications, as is now done for carbon nanotubes [65-67]. The results discussed above also demonstrated the excellent performance of the graphene/nanotube mixture in regulating hMSC chondrogenic differentiation. As one of the most versatile nanomaterials for biomedical applications [21, 68], carbon nanomaterials can also alter nano surface topography of tissue scaffolds and be leveraged to bolster very weak scaffolds and render them promising for cartilage tissue engineering applications that otherwise would be less than ideal. Specifically here we have shown that our scaffolds have very advantageous properties pertaining to initial characterization and cytocompatibility. They have compression profiles similar to cartilage, they have an affinity for fibronectin absorption, and they have visually observable qualities similar to cartilage, specifically SEM confirmation that composite material can still be electrospun into collagen-like fibrous mats of a dimension suitable for cellular activity. These characteristics are then supported by cytocompatibility tests, which show that undifferentiated hMSCs can adhere and proliferate better on our constructs. Our confocal images also show high densities of welldistributed cells which have begun to form intertwined filopodia, indicative of native tissue [6972]. 
Often in vitro culture, stem cells will cease or slow production of some ECM components, if production of others becomes more active [73, 74]. For example, a culture of hMSCs that begins to deposit GAG may, over time and increased GAG concentration, upregulate GAG productions. If, due to for whatever other factors are present, the culture environment favors this hypothetical GAG deposition, the concentration could increase to a point that it actually self-promotes even more GAG synthesis from the cells, in an almost recursive fashion. Thus, in this way, it is possible that the increased GAG production on our scaffolds may have a little adversely effected collagen type II deposition, providing possible explanation for the high GAG contents correlating to decreased collagen type II. Still, this could be counteracted with more finely tuned nanomaterials to exactly match the compressive strength of native cartilage. Since GAG is the compressive component of the tissue nanostructure, this would theoretically have a profound impact of the response to GAG synthesis, and create a more finely regulated GAG production environment. Additional methods, like mechanical / electrical stimulation in culture or the inclusion of chemical signaling factors could also further control the culture environment, and direct certain specific materials, or control cell migration and proliferation aside from differentiation and lineage progression or tissue formation [25, 75-77].

\section{Conclusion}

In this study, a carbon nanomaterial composed of graphene nanoplatelets and SWCNTs was produced using an arc discharge method. After thorough characterization, a series of novel electrospun fibrous scaffold incorporating the carbon nanomaterials (both with and without polyL-lysine coating) were fabricated to mimic natural cartilage ECM, and regulate hMSC behaviors. Our results demonstrated that the poly-L-lysine and graphene/nanotube containing scaffolds have 
improved mechanical properties and more homogenous fiber morphology and surface properties. More importantly, our results showed that the poly-L-lysine coated graphene/nanotube scaffolds showed good cytocompatibility, which can lead to enhance hMSC growth and chondrogenic differentiation in vitro. In addition, both arc discharge produced graphene/nanotube and poly-Llysine can contribute to regulating different MSC behaviors when incorporated into novel electrospun composite fibers, and thus worth further exploration for improving cartilage formation in in vivo studies.

\section{Acknowledgments:}

This work was supported by the Clinical and Translational Science Institute at Children's National (CTSI-CN) and by the George Washington Institute for Biomedical Engineering (GWIBE). This work was also supported in part by the National Science Foundation (EAGER:

Exploring plasma mechanism of synthesis of graphene in arc discharge, NSF Award No. 1249213). 


\section{References:}

[1] Giannoni P, Narcisi R. Nano-approaches in cartilage repair. Journal of applied biomaterials \& biomechanics : JABB 2009;7:1-12.

[2] Matsiko A, Levingstone T, Brien F. O'Advanced strategies for articular cartilage defect repair. Materials doi 103390ma607 2063;6 SRC - GoogleScholar:637-68.

[3] Huselstein C, Li Y, He X. Mesenchymal stem cells for cartilage engineering. Bio-medical materials and engineering 2012;22:69-80.

[4] Sharma RK, Balhara YPS, Sagar R, Deepak KK, Mehta M. Heart rate variability study of childhood anxiety disorders. Journal of cardiovascular disease research 2011;2:115-22.

[5] Zhang L, Hu J, Athanasiou KA. The role of tissue engineering in articular cartilage repair and regeneration. Critical Reviews in Biomedical Engineering 2009;37:1-57.

[6] Bianco P, Robey PG. Stem cells in tissue engineering. Nature 2001;414:118-21.

[7] Tuli R, Tuli S, Nandi S, Wang ML, Alexander PG, Haleem-Smith H, et al. Characterization of multipotential mesenchymal progenitor cells derived from human trabecular bone. Stem Cells 2003;21:681-93.

[8] Mhashilkar AM, Atala A. Advent and maturation of regenerative medicine. Current stem cell research \& therapy 2012;7:430-45.

[9] Mankikar SD. Stem cells: a new paradigm in medical therapeutics. J Long Term Eff Med Implants 2010;20:219-50.

[10] Schraufstatter IU, Discipio RG, Khaldoyanidi S. Mesenchymal stem cells and their microenvironment. Front Biosci 2011;16:2271-88.

[11] Charbord P. Bone marrow mesenchymal stem cells: historical overview and concepts. Hum Gene Ther 2010;21:1045-56. 
[12] Park JY, Lee DH, Lee EJ, Lee SH. Study of cellular behaviors on concave and convex microstructures fabricated from elastic PDMS membranes. Lab on a chip 2009;9:2043-9.

[13] Ripamonti U, Roden L. Biomimetics for the induction of bone formation. Expert review of medical devices 2010;7:469-79.

[14] Bakhru S, Nain AS, Highley C, Wang J, Campbell P, Amon C, et al. Direct and cell signaling-based, geometry-induced neuronal differentiation of neural stem cells. Integrative biology : quantitative biosciences from nano to macro 2011;3:1207-14.

[15] Kilian KA, Bugarija B, Lahn BT, Mrksich M. Geometric cues for directing the differentiation of mesenchymal stem cells. Proceedings of the National Academy of Sciences of the United States of America 2010;107:4872-7.

[16] Oh S, Brammer KS, Li YS, Teng D, Engler AJ, Chien S, et al. Stem cell fate dictated solely by altered nanotube dimension. Proc Natl Acad Sci U S A 2009;106:2130-5.

[17] Lund AW, Yener B, Stegemann JP, Plopper GE. The natural and engineered 3D microenvironment as a regulatory cue during stem cell fate determination. Tissue Eng Part B Rev 2009;15:371-80.

[18] Castro NJ, Hacking SA, Zhang LG. Recent progress in interfacial tissue engineering approaches for osteochondral defects. Ann Biomed Eng 2012;40:1628-40.

[19] Zhang L, Li JY, Lee JD. Nanotechnology for Cartilage and Bone Regeneration. In: Webster TJ, editor. Nanomedicine: technologies and applications: Woodhead Publishing Limited; 2012. p. 571-98.

[20] Zhang L, Hemraz UD, Fenniri H, Webster TJ. Tuning cell adhesion on titanium with osteogenic rosette nanotubes. J Biomed Mater Res A 2010;95:550-63. 
[21] Zhang L, Ercan B, Webster TJ. Carbon Nanotubes and Nanofibers for Tissue Engineering Applications. In: Liu C, editor. Carbon: Research Signpost; 2009.

[22] Zhang L, Webster TJ. Nanotechnology and Nanomaterials: Promises for Improved Tissue Regeneration. Nanotoday 2009;4:66-80.

[23] Sun L, Zhang L, Hemraz UD, Fenniri H, Webster TJ. Bioactive rosette nanotubehydroxyapatite nanocomposites improve osteoblast functions. Tissue engineering Part A 2012;18:1741-50.

[24] Castro NJ, O'Brien C, Zhang LG. Biomimetic Biphasic 3D Nanocomposite Scaffold for Osteochondral Regeneration AICHE Journal 2014;60:432-42

[25] Holmes B, Castro NJ, Li J, Keidar M, Zhang LG. Enhanced human bone marrow mesenchymal stem cell functions in novel 3D cartilage scaffolds with hydrogen treated multi-walled carbon nanotubes. Nanotechnology 2013;24:365102.

[26] Childs A, Hemraz UD, Castro NJ, Fenniri H, Zhang LG. Novel biologically-inspired rosette nanotube PLLA scaffolds for improving human mesenchymal stem cell chondrogenic differentiation. Biomed Mater 2013;8:065003.

[27] Yoshimoto H, Shin YM, Terai H, Vacanti JP. A biodegradable nanofiber scaffold by electrospinning and its potential for bone tissue engineering. Biomaterials 2003;24:207782.

[28] Smith LA, Ma PX. Nano-fibrous scaffolds for tissue engineering. Colloids Surf B Biointerfaces 2004;39:125-31.

[29] Nair LS, Bhattacharyya S, Laurencin CT. Development of novel tissue engineering scaffolds via electrospinning. Expert Opin Biol Ther 2004;4:659-68. 
[30] Ma Z, Kotaki M, Inai R, Ramakrishna S. Potential of nanofiber matrix as tissue-engineering scaffolds. Tissue Eng 2005;11:101-9.

[31] Thorvaldsson A, Stenhamre H, Gatenholm P, Walkenström P. Electrospinning of Highly Porous Scaffolds for Cartilage Regeneration. Biomacromolecules 2008;9:1044-9.

[32] Holmes B, Castro NJ, Zhang LG, Zussman E. Electrospun fibrous scaffolds for bone and cartilage tissue generation: recent progress and future developments. Tissue Eng Part B Rev 2012;18:478-86.

[33] Liu J, Leung P, Yang A. Breastfeeding and Active Bonding Protects against Children's Internalizing Behavior Problems. Nutrients 2013;6:76-89.

[34] Sayyar S, Murray E, Thompson B, Gambhir S, Officer D, Wallace G. Covalently linked biocompatible graphene/ polycaprolactone composites for tissue engineering2012.

[35] Mingyu C, Kai G, Jiamou L, Yandao G, Nanming Z, Xiufang Z. Surface modification and characterization of chitosan film blended with poly-L-lysine. Journal of biomaterials applications 2004;19:59-75.

[36] Steward AJ, Wagner DR, Kelly DJ. The pericellular environment regulates cytoskeletal development and the differentiation of mesenchymal stem cells and determines their response to hydrostatic pressure. European cells \& materials 2013;25:167-78.

[37] Morgan EF, Salisbury Palomares KT, Gleason RE, Bellin DL, Chien KB, Unnikrishnan GU, et al. Correlations between local strains and tissue phenotypes in an experimental model of skeletal healing. Journal of biomechanics 2010;43:2418-24.

[38] Kalbacova M, Broz A, Kong J, Kalbac M. Carbon, . doi: 10.1016/j.carbon..07.045. 2010;48 SRC - GoogleScholar:4323-9. 
[39] Nayak TR, Andersen H, Makam VS, Khaw C, Bae S, Xu X, et al. Graphene for controlled and accelerated osteogenic differentiation of human mesenchymal stem cells. ACS nano 2011;5:4670-8.

[40] Wang M, Castro NJ, Li J, Keidar M, Zhang LG. Greater osteoblast and mesenchymal stem cell adhesion and proliferation on titanium with hydrothermally treated nanocrystalline hydroxyapatite/magnetically treated carbon nanotubes. J Nanosci Nanotechnol 2012;12:7692-702.

[41] Im O, Li J, Wang M, Zhang LG, Keidar M. Biomimetic three-dimensional nanocrystalline hydroxyapatite and magnetically synthesized single-walled carbon nanotube chitosan nanocomposite for bone regeneration. Int J Nanomedicine 2012;7:2087-99.

[42] Day RM, Boccaccini AR, Maquet V, Shurey S, Forbes A, Gabe SM, et al. In vivo characterisation of a novel bioresorbable poly(lactide-co-glycolide) tubular foam scaffold for tissue engineering applications. Journal of materials science Materials in medicine 2004;15:729-34.

[43] Kruyt MC, van Gaalen SM, Oner FC, Verbout AJ, de Bruijn JD, Dhert WJ. Bone tissue engineering and spinal fusion: the potential of hybrid constructs by combining osteoprogenitor cells and scaffolds. Biomaterials 2004;25:1463-73.

[44] Cooper HLR, Mishra G, Huang X, Pender-Cudlip M, Austin RN, Shanklin J, et al. Parallel and competitive pathways for substrate desaturation, hydroxylation, and radical rearrangement by the non-heme diiron hydroxylase AlkB. Journal of the American Chemical Society 2012;134:20365-75.

[45] Sanchez VC, Jachak A, Hurt RH, Kane AB. Biological interactions of graphene-family nanomaterials: an interdisciplinary review. Chemical research in toxicology 2012;25:15-34. 
[46] Akhavan O, Ghaderi E, Shahsavar M. Graphene nanogrids for selective and fast osteogenic differentiation of human mesenchymal stem cells. Carbon 2013;59:200-11.

[47] Galpaya D, Wang M, Liu M, Motta N, Waclawik E, Yan C. Recent advances in fabrication and characterization of graphene-polymer nanocomposites. Graphene doi 104236graphene1 2005;1 SRC - GoogleScholar:30-49.

[48] Volotskova O, Fagan JA, Huh JY, Phelan FR, Shashurin A, Keidar M. Tailored Distribution of Single-Wall Carbon Nanotubes from Arc Plasma Synthesis Using Magnetic Fields. ACS Nano 2010;4:5187-92.

[49] Volotskova O, Levchenko I, Shashurin A, Raitses Y, Ostrikov K, Keidar M. Single-step synthesis and magnetic separation of graphene and carbon nanotubes in arc discharge plasmas. Nanoscale 2010;2:2281-5.

[50] Wang M, Cheng X, Zhu W, Holmes B, Keidar M, Zhang LG. Design of biomimetic and bioactive cold plasma-modified nanostructured scaffolds for enhanced osteogenic differentiation of bone marrow-derived mesenchymal stem cells. Tissue Eng Part A 2014;20:1060-71.

[51] Dolatshahi-Pirouz A, Jensen T, Kraft DC, Foss M, Kingshott P, Hansen JL, et al. Fibronectin adsorption, cell adhesion, and proliferation on nanostructured tantalum surfaces. ACS Nano 2010;4:2874-82.

[52] Webster TJ, Ergun C, Doremus RH, Siegel RW, Bizios R. Specific proteins mediate enhanced osteoblast adhesion on nanophase ceramics. J Biomed Mater Res 2000;51:47583. 
[53] Vagaská B, Bacáková L, Filová E, Balík K. Osteogenic cells on bio-inspired materials for bone tissue engineering. Physiological research / Academia Scientiarum Bohemoslovaca 2010;59:309-22.

[54] Webster TJ, Schadler LS, Siegel RW, Bizios R. Mechanisms of enhanced osteoblast adhesion on nanophase alumina involve vitronectin. Tissue Eng 2001;7:291-301.

[55] Thorpe SD, Nagel T, Carroll SF, Kelly DJ. Modulating gradients in regulatory signals within mesenchymal stem cell seeded hydrogels: a novel strategy to engineer zonal articular cartilage. PloS one 2013;8:e60764.

[56] Lee TY, Chen WS, Huang YA, Liu TW, Hwang E, Tseng CP. Application of aurintricarboxylic acid for the adherence of mouse P19 neurons and primary hippocampal neurons to noncoated surface in serum-free culture. Biotechnology progress 2012.

[57] Wiegand C, White R. Microdeformation in wound healing. Wound repair and regeneration : official publication of the Wound Healing Society [and] the European Tissue Repair Society 2013;21:793-9.

[58] $\mathrm{Hu} \mathrm{B}$, El Haj AJ, Dobson J. Receptor-targeted, magneto-mechanical stimulation of osteogenic differentiation of human bone marrow-derived mesenchymal stem cells. International journal of molecular sciences 2013;14:19276-93.

[59] Viana SL, Machado BB, Mendlovitz PS. MRI of subchondral fractures: a review. Skeletal radiology 2014.

[60] Lisbona MP, Pamies A, Ares J, Almirall M, Navallas M, Solano A, et al. Association of Bone Edema with the Progression of Bone Erosions Quantified by Hand Magnetic Resonance Imaging in Patients with Rheumatoid Arthritis in Remission. The Journal of rheumatology 2014. 
[61] Jiang CC, Chiang H, Liao CJ, Lin YJ, Kuo TF, Shieh CS, et al. Repair of porcine articular cartilage defect with a biphasic osteochondral composite. Journal of orthopaedic research : official publication of the Orthopaedic Research Society 2007;25:1277-90.

[62] Qiu Y, Lei J, Koob TJ, Temenoff JS. Cyclic tension promotes fibroblastic differentiation of human MSCs cultured on collagen-fibre scaffolds. Journal of tissue engineering and regenerative medicine 2014 .

[63] Cui X, Breitenkamp K, Finn MG, Lotz M, D'Lima DD. Direct human cartilage repair using three-dimensional bioprinting technology. Tissue Eng Part A 2012;18:1304-12.

[64] San Antonio JD, Jacenko O, Yagami M, Tuan RS. Polyionic regulation of cartilage development: promotion of chondrogenesis in vitro by polylysine is associated with altered glycosaminoglycan biosynthesis and distribution. Developmental biology 1992;152:32335 .

[65] Paladugu MC, Maneesh K, Nair PK, Haridoss P. Synthesis of carbon nanotubes by arc discharge in open air. Journal of nanoscience and nanotechnology 2005;5:747-52.

[66] Dillon AC, Yudasaka M, Dresselhaus MS. Employing Raman spectroscopy to qualitatively evaluate the purity of carbon single-wall nanotube materials. Journal of nanoscience and nanotechnology 2004;4:691-703.

[67] Gao F, Xie SY, Huang RB, Zheng LS. Significant promotional effect of CCl4 on fullerene yield in the graphite arc-discharge reaction. Chem Commun (Camb) 2003:2676-7.

[68] Tran PA, Zhang L, Webster TJ. Carbon nanofibers and carbon nanotubes in regenerative medicine. Adv Drug Deliv Rev 2009;61:1097-114. 
[69] Huynh MH, Sage EH, Ringuette M. A calcium-binding motif in SPARC/osteonectin inhibits chordomesoderm cell migration during Xenopus laevis gastrulation: evidence of counter-adhesive activity in vivo. Development, growth \& differentiation 1999;41:407-18.

[70] Hazarika P, Dham N, Patel P, Cho M, Weidner D, Goldsmith L, et al. Flotillin 2 is distinct from epidermal surface antigen (ESA) and is associated with filopodia formation. Journal of cellular biochemistry 1999;75:147-59.

[71] Greenburg G, Hay ED. Epithelia suspended in collagen gels can lose polarity and express characteristics of migrating mesenchymal cells. The Journal of cell biology 1982;95:333-9.

[72] Bouvet J. [Differentiation and ultrastructure of the distal skeleton of the pectoral fin of the native trout (Salmo trutta fario L.). I. Differentiation and ultrastructure of the actinotrichia]. Archives d'anatomie microscopique et de morphologie experimentale 1974;63:79-96.

[73] Matsiko A, Levingstone TJ, O'Brien FJ, Gleeson JP. Addition of hyaluronic acid improves cellular infiltration and promotes early-stage chondrogenesis in a collagen-based scaffold for cartilage tissue engineering. Journal of the mechanical behavior of biomedical materials 2012;11:41-52.

[74] Ye R, Hao J, Song J, Zhao Z, Fang S, Wang Y, et al. Microenvironment is Involved in Cellular Response to Hydrostatic Pressures During Chondrogenesis of Mesenchymal Stem Cells. Journal of cellular biochemistry 2013.

[75] Brown JP, Finley VG, Kuo CK. Embryonic mechanical and soluble cues regulate tendon progenitor cell gene expression as a function of developmental stage and anatomical origin. Journal of biomechanics 2014;47:214-22. 
[76] Chung KM, Hsu SC, Chu YR, Lin MY, Jiaang WT, Chen RH, et al. Fibroblast Activation Protein (FAP) Is Essential for the Migration of Bone Marrow Mesenchymal Stem Cells through RhoA Activation. PloS one 2014;9:e88772.

[77] Lima EG, Bian L, Mauck RL, Byers BA, Tuan RS, Ateshian GA, et al. The effect of applied compressive loading on tissue-engineered cartilage constructs cultured with TGF-beta3. Conf Proc IEEE Eng Med Biol Soc 2006;1:779-82. 